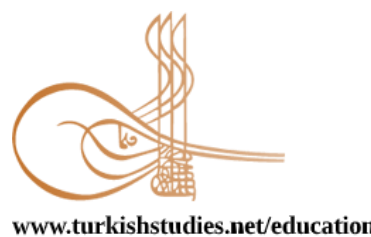

Turkish Studies - Educational Sciences

\title{
Örgütsel İklimin Bilgi Yönetimi Süreci Üzerindeki Etkisinin İncelenmesi*
}

\author{
The Effects of Organizational Climate on Knowledge Management Process
}

\author{
Esra Töre**
}

\begin{abstract}
In recent years, knowledge management process has gained great importance in business and management literature. Decision-making, communication, learning, sharing, management and innovation processes work more effectively in organizations that use knowledge management processes actively. Customer relations, service quality and employee satisfaction are at a higher level. In this context, the aim of this study is to examine the effect of organizational climate on knowledge management process. Relational survey model was used in the study. The sample group of the study consists of 218 teachers working in public schools in Küçükçekmece district of İstanbul. In the research, "personal information form", "organizational climate scale" and "knowledge management scale" were used as data collection tools. Descriptive statistics, factor analysis, regression analysis, T-test and ANOVA test were used for data analysis. As a result of the analyzes, it has been found that organizational climate affects the information management process. Teachers' perceptions of the information management process differ according to age, working year and position variables. The perceptions of teachers regarding the level of realization of the information management process are higher between the ages of 40-49 than those of other teachers. The perceptions of teachers, whose working year is between 16-20 years, regarding the level of realization of the information management process are higher than those of other teachers. It has been found that school principals have higher perceptions about the level of realization of the information management process than the deputy principals and teachers. It was found that teachers' perceptions about the information management process did not differ according to whether they received training on information management and gender. Research findings are discussed, suggestions are made for the education sector and researchers.
\end{abstract}

Structured Abstract: Nowadays, in a competitive and dynamic business environment, information has become one of the most important assets (Fong et al., 2009: 1348). The core competence and high performance of organizations is built on knowledge and intellectual capital. The sustainability of the competitive advantage is made possible by the production, sharing and use of important information for the organization (Tabrizi et al., 2010: 722).

The purpose of knowledge management is to increase the competitiveness of the organization through the employees in the organization, to provide flexibility and innovation (Zhao, 2010: 169). Decision making, communication, learning, sharing, management and innovation processes work more effectively in organizations where information management is effective. Customer relations, service quality and job satisfaction of employees are higher (Anand and Singh, 2011: 936).

\footnotetext{
* Makale verileri 2018 yılında toplanılmıştır.

** Dr. Öğr. Üyesi, İstanbul Sabahattin Zaim Üniversitesi, Eğitim Fakültesi, Eğitim Bilimleri Bölümü

Asst. Prof, Istanbul Sabahattin Zaim University, Faculty of Education, Department of Educational Sciences

ORCID 0000-0001-9133-6578

esra.tore@izu.edu.tr

Cite as/ Atıf: Töre, E. (2020). Örgütsel iklimin bilgi yönetimi süreci üzerindeki etkisinin incelenmesi. Turkish Studies

- Education, 15(3), 2137-2151. https://dx.doi.org/10.29228/TurkishStudies.40054

Received/Geliş: 07 December/Aralık 2019

Accepted/Kabul: 21 June/Haziran 2020

Checked by plagiarism software

Copyright (C) INTAC LTD, Turkey 
A comprehensive process for knowledge management needs to be designed. The process includes many functions such as defining, acquiring, developing, disseminating and disseminating it within the organization, using it for purposes and redesigning the process by evaluating this usage for the organization (Kılıç, 2007: 29).

The knowledge management process, which has existed for a long time but was conceptualized in the 2000 s, is affected by many variables. Human, process and technology can be mentioned in three basic variables for the healthy execution of the process (Fong et al., 2009: 1349). How the employee perceives the organization is explained with the concept of organizational climate. Organizational climate can be defined as the environment of employees in an organization. We cannot see the organizational climate, we cannot touch it, but it is there. Organizational climate, such as air in a room, affects everything that happens in the workplace (Dawis and Newstrom, 1985: 23).

Organizational climate is a general concept that reflects the quality of organizational life. Affecting the behavior of individuals in the organization, distinguishing the characteristics of an organization from others (Hoy, 1990: 151). In other words, organizational climate is typical or characteristic of a particular business environment (Porter et al., 1989: 456). Organizational climate is the effects of the experiences and the behaviors of the employees, depending on the continuity of the quality in the institution (Virtanen, 2000: 341).

When the literature is examined, it is seen that there are many theoretical and empirical studies indicating that organizational culture is effective on knowledge management (Yusoff and Omar, 2011; Davenport and Prusak, 2000; Janz and Prasampanic, 2003; Moffett et al, 2003). Studies show that organizational culture that supports learning makes the knowledge management process more successful. Studies examining the impact of organizational climate on knowledge management are not sufficient in the literature. In the studies, it was found that positive organizational climate positively affected the information sharing process, which is a dimension of knowledge management process (Bock et al., 2005; Chen et al., 2012).

In this context, the aim of this study is to examine the effect of organizational climate on knowledge management process. In addition, the following research hypotesis were sought in this study:

Teachers' perceptions about the realization level of knowledge management process does it differ significantly according to,
a) gender,
b) age,
c) tenure,
d) whether or not to receive training in information management,
e) position.

\section{Method}

The sample of the study consists of 218 teachers working in public schools in Küçükçekmece district of İstanbul. The sample was determined by stratified sampling. Subgroups in the universe were identified and represented in the sample in accordance with their current proportions in the universe (Karasar, 2008).

The research questionnaire was applied in six public schools with the necessary permissions. 240 questionnaires were sent to the participants and 218 of the questionnaires were evaluated. During the application, the questionnaire was delivered face to face to the participants. The responses were analyzed by the prepared statistics package program.

In the research, personal information form, organizational climate scale, and knowledge management scale were used as data collection tools.

The personal information form prepared by the researcher consists of five questions including the gender, age, tenure, status of whether or not to receive training in information management, and position information of the participants in the study group.

The Organizational Climate Scale was developed by Litwin and and Stringer (1968) and includes 45 items. The scale consisting of nine sub-dimensions as structure, responsibility, reward, temperance, support, 
standards, conflict, identity and risk. It was translated into Turkish by Nilgün Kalfazade Birim (1993) (cited in Tüzün, 2005). Participants were asked to indicate how much they agree with these statements on a scale extending from "completely agree" to "never agree". As a result of the reliability analysis, the reliability of the scale was found to be 93\% (cronbach's alpha =0.939) (Töre, 2006: 27).

Knowledge Management Scale was developed by the researcher by scanning the relevant literature and taking expert opinions. The scale consists of 22 items in three sub-dimensions as "knowledge collection", "knowledge production and sharing", "knowledge storage and use", Participants were asked to indicate how much they agree with these statements on a scale extending from "completely agree" to "never agree". As a result of the reliability analysis, the scale was found to be $95 \%$ reliable (Cronbach's alpha $=0.947$ ).

\section{Results}

The data of the research were analyzed by using the prepared statistical package program. Descriptive statistics, factor analysis, regression analysis, T-test and ANOVA test were used for data analysis. As a result of the analyzes, it was found that;

Organizational climate significantly and positively effect on the knowledge management process [(B $=.758),(\mathrm{p}<0.01)]$ and explained the model by $57 \%$.

Organizational climate has a significant and positive effect on "knowledge production and sharing" sub-dimension of the knowledge management process [ $(\mathrm{B}=.739),(\mathrm{p}<0.01)]$ and explained the model by $54 \%$.

Organizational climate has a significant and positive effect on "knowledge storage and use" subdimension of the knowledge management process [ $(\mathrm{B}=.665),(\mathrm{p}<0.01)]$ and explained the model by $44 \%$.

Organizational climate has a significant and positive effect on "knowledge collection" sub-dimension of the knowledge management process $[(\mathrm{B}=.436(\mathrm{p}<0.01)]$ and explained the model by $18 \%$.

As a result of T-tests and ANOVA tests, teachers' perceptions about knowledge management process differ according to age, tenure and position variables; but do not differ gender and knowledge management.

(a) The perceptions of the teachers who are 50 years and over about the realization level of knowledge management process are higher than the teachers between 20-29 years and 30-39 years $(\mathrm{F}=4.067, \mathrm{p}<0.01)$.

(b) The perceptions of the realization level of the knowledge management process of teachers 20 years and over in tenure are higher than the teachers whose tenure are between 1-5 years, 6-10 years and 11-15 years $(\mathrm{F}=4.462, \mathrm{p}<0.05)$.

(c) School managers' perception of knowledge management process realization level is higher than vice principals and teachers $(\mathrm{F}=5.484, \mathrm{p}<0.01)$.

\section{Discussion and Suggestions}

Chen and Huang (2007) examined the effects of organizational climate and structure on knowledge management, and found that innovative and supportive climate had a positive meaningful relationship with knowledge management. Lee et al. (2006) found that climate maturity, which includes the concepts of learningoriented, trust and employee engagement, positively effect on knowledge management performance. Lin and Lee (2006) found that organizational climate significantly effects on perceived relative advantage, compliance and complexity, and this positively affects the intention to promote knowledge sharing. Zhao (2010) found that knowledge management process is more effective in the organizational environment where positive leadership, cooperation and interaction occur. Positive organizational climate has a positive effect on the knowledge sharing process, which is a dimension of knowledge management (Li et al., 2010, Villamizar Reyes, Castañeda Zapata, 2014; Bock et al., 2005; Chen et al, 2012). Bock et al. (2005) found that knowledge sharing is more effective in an organizational climate where fair, innovative and close relationships are dominant. Li et al. (2010) found that organizational climate (friendly relations, innovation, and fairness) affects the information sharing behavior of employees in information technology enterprises. These findings support our research.

In line with the findings of the research, the following suggestions are included:

It is recommended that educational organizations, where knowledge management process is a key variable, should include strategies to make their organizational climate positive. 
The perceptions of teachers with a realization level of knowledge management process between 1-10 years were lower than those of more experienced teachers. It is thought that it would be beneficial for experienced teachers to guide less experienced teachers about the process.

Perceptions of school principals about the level of realization of knowledge management process were lower than vice principals and teachers. Qualitative studies can be conducted to investigate the causes of this situation.

The research was limited to teachers working in Küçükçekmece district of Istanbul province and it is suggested to be done in different provinces and different occupational groups.

In this research, knowledge management process was evaluated by teachers. In subsequent research, students, parents and other stakeholders are included in the evaluation process as more comprehensive study.

It is recommended to examine other organizational and individual variables that affect the knowledge management process.

Keywords: Knowledge Management Process, Organizational Climate, Teacher.

Öz: Son yıllarda bilgi yönetimi süreci iş ve yönetim yazınında büyük önem kazanmıştır. Bilgi yönetim süreçlerini aktif kullanan örgütlerde karar verme, iletişim, öğrenme, paylaşım, yönetim, inovasyon süreçleri daha etkili çalışmaktadır. Müşteri ilişkileri, servis kalitesi, çalışanların iş doyumu daha üst düzeydedir. Bu kapsamda bu çalışmanın amacı, örgütsel iklimin bilgi yönetimi süreci üzerindeki etkisini incelemektir. Çalışmada ilişkisel tarama modeli kullanılmıştır. Çalışmanın örneklem grubunu İstanbul İli Küçükçekmece ilçesinde bulunan, devlet okullarında çalışan 218 öğretmen oluşturmaktadır. Araştırmada veri toplama aracı olarak "kişisel bilgi formu", "örgütsel iklim ölçeği” ve "bilgi yönetimi ölçeği” kullanılmıştır. Verilerin analizinde tanımlayıcı istatistikler, faktör analizi, regreyon analizi, T-testi ve ANOVA testine başvurulmuştur. Yapılan analizler sonucunda, örgütsel iklimin bilgi yönetimi sürecinini etkilediği bulunmuştur. Öğretmenlerin bilgi yönetim sürecine ilişkin algıları yaş, çalışma yılı ve pozisyon değişkenlerine göre farklılık göstermektedir. 40-49 yaş arası olan öğretmenlerin bilgi yönetimi sürecinin gerçekleşme düzeyine ilişkin algıları, diğer öğretmenlerin algılarına göre daha yüksektir. Çalışma yılı 16-20 yıl arası olan öğretmenlerin bilgi yönetimi sürecinin gerçekleşme düzeyine ilişkin algıları diğer öğretmenlerin algılarına göre daha yüksektir. Okul müdürlerinin, müdür yardımcısı ve öğretmenlere göre bilgi yönetimi sürecini gerçekleşme düzeyine ilişkin algılarının daha yüksek olduğu bulunmuştur. Öğretmenlerin bilgi yönetim sürecine ilişkin algılarının cinsiyet ve bilgi yönetimi konusunda eğitim alıp almama değişkenlerine göre ise farklılık göstermediği bulunmuştur. Araştırma bulguları tartışılmış, eğitim sektörü ve araştırmacılar için önerilerde bulunulmuştur.

Anahtar Kelimeler: Bilgi Yönetimi Süreci, Örgütsel İklim, Öğretmen.

\section{Giriş}

Rekabetçi ve dinamik iş çevresinin olduğu günümüzde bilgi en önemli varlıklardan biri haline gelmiştir (Fong vd., 2009:1348). Organizasyonların temel yeteneği ve yüksek performans1, bilgi ve entelektüel sermaye üzerine kurulmuştur. Rekabet avantajının sürdürülebilirliği, organizasyon için önemli bilginin üretilmesi, paylaşılması ve kullanılması ile mümkün hale gelmektedir (Tabrizi, R. S., Foong, Ebrahimi, 2010:722). Dünya ekonomisi endüstriyel üretim ve ürün odaklı olmaktan uzaklaşarak, bilgi ve hizmete dayalı şekilde değişmiştir. Artık başlıca varlık enformasyon veya bilgidir (Walczack, 2005:331). Örgütsel bilgi; örgütsel gelişme ve genişlemenin en önemli kaynağı olarak değerli ve görünmez bir zenginliktir. Bu şekliyle tüm organizasyonlar için bir nitelik ve nicelik göstergesi olmaktadır. (Ghorbani vd., 2011:2032).

Günümüz örgütlerinde bilgi ortak amaçlar için takım çalışmasını gerektiren örgütsel süreçleri ifade eder. Giderek yaygın bir biçimde bilgi örgütsel kaynak olarak görülmekte ve bilginin yönetilmesi şansa bırakılmayacak bir konu haline gelmektedir (Çetinkaya, 2012:158). Bilgi yönetimi doğru bilginin edinilerek, doğru zamanda, doğru insana ulaştırılmasıdır (Saade vd., 2011:37). Bilgi yönetiminin amacı örgütte çalışanlar yolu ile örgütün rekabet gücünü arttırmak, esnekliği ve 
inovasyonu sağlamaktır (Zhao, 2010:169). Bilgi yönetiminin etkin olduğu örgütlerde karar verme, iletişim, öğrenme, paylaşım, yönetim, inovasyon süreçleri daha etkili çalışmaktadır. Müşteri ilişkileri, servis kalitesi, çalışanların iş doyumu daha üst düzeydedir (Anand ve Singh, 2011:936).

Bilgi yönetimi için kapsamlı bir sürecin tasarlanması gerekmektedir. Organizasyon için bilginin tanımlanması, edinilmesi, geliştirilmesi, örgüt içinde paylaşılarak yaygınlaştırılması, amaçlara yönelik kullanılması ve bu kullanımın değerlendirilerek sürecin yeniden tasarlanması gibi kapsamlı pek çok fonksiyonu içeren bir süreçtir (Kılıç, 2007:29). Bilgi yönetimi sürecini bilginin yaratılması, organize edilmesi, paylaşılması ve uygulanması olmak üzere 4 başlıkta incelenebilir. BSoruilgini yaratılması, yeni fikirlerin, bakıș açılarının alındığı; farkporterlı süreçlerin kombine edildiği aşamadır. Bilginin organize edilmesi, toplanması, kaydedilmesi ve depolanmasını içerir. Bilginin paylaşılması, insanlar arasında bilginin karşılıklı olarak dağılması, yayılmasıdır. Bilginin kullanımı ise bilginin eyleme dönüştürülmesi, örgütün üretim sürecine yansıtılmasıdır (Fard ve Selseleh, 2010:300-301).

Çınar (2004:2) bilgi yönetimi sürecini bilginin elde edilmesi/üretilmesi, paylaşılması, kullanılması ve depolanması olmak üzere 4 temel aşamada tanımlar. Bilginin elde edilmesi/üretilmesi örgütün diş çevresinde gelişen ve örgütü ilgilendiren formal ve/veya informal bilgilerle, açık ve örtük bilgilerin örgüt içine alınması, iç bilgi ve deneyimlerle çözümlenerek yeni bilgi ve düşüncelerin oluşturulmasıdır. Sürecin özünde çalışanların örtük bilgilerini (bireylerin oldukça öznel birikim, sezgi ve içgüdülerini) paylaşmak, bunları kullanıma hazır hale getirmek ve tüm örgüt için denemek vardır (Kılıç, 2007:35). Bilginin paylaşılması, örgüt içinde her türlü bilginin ona gereksinimi olana gerektiği zamanda ve uygun biçimde sunulmasıdır. Üretilen/elde edilen bilginin örgütsel amaçlar doğrultusunda kullanılabilmesi için bilgi paylaşımına ihtiyaç vardır. Bilginin kullanılması, ürüne dönüştürülmesidir. Bilgi ancak uygun şekilde kullanılırsa örgütsel performansı arttırır ve rekabet avantajına dönüşebilir (Kourik ve Maher, 2008:5). Bilgini depolanması ise bilgiyi üreten ya da kullanan örgütün, o bilgiyi yeniden kullanma amacı ile saklamasıdır.

Çok uzun zamandır var olan ancak 2000'li yıllarda kavramlaşan bilgi yönetimi süreci pek çok değişkenden etkilenmektedir. Sürecin sağlıklı yürütülebilmesinde insan, süreç ve teknoloji olmak üzere üç temel değişkenden bahsedilebilir (Fong vd., 2009:1349). Çalışanın örgütü nasıl algıladığı, örgütsel iklim kavramı ile açıklanır. Örgütsel iklim bir kurumdaki çalışanların çevresi olarak tanımlanabilir. Örgütsel iklimi göremeyiz, ona dokunamayız fakat o oradadır. Bir odanın içerisindeki hava gibi örgütsel iklim, işyerinde olan biten her şeyi etkiler (Dawis ve Newstrom, 1985:23). Bireyin çevresi, o bireyin davranışlarının temel belirleyicisi niteliğindedir. Son zamanlarda çalışanın davranışı üzerinde sosyal, durumsal ve örgütsel çevrenin etkisi artmıştır. Temel varsayım bireylerin davranışlarının algıladıklarından etkilendiği yönündedir. Bu nedenle iklim çalışmalarının odak noktası bireyin algılarıdır (Halis ve Uğurlu, 2008:103).

Örgütsel iklim çalışmalarının kökeni Kurt Lewin'e dayanır. Lewin "iklim" i yaz kampındaki bir grup çocuğun tutumları, duyguları ve düşünceleri olarak tanımlamıştır. Lewin ve arkadaşları (1939) örgütsel iklimi, belirli bir çevrede çalışan bireyin kendini nasıl hissettiğini algılaması olarak tanımlarlar. Örgütsel iklim örgütsel yaşamın kalitesini yansıtan genel bir kavramdır. Örgütteki bireylerin davranışlarını etkileyen, bir örgütü diğerlerinden ayıran karakteristik özelliklerdir (Hoy, 1990:151). Diğer bir deyişle, örgütsel iklim belirli bir iş çevresinin tipik ya da karakteristik niteliğidir (Porter vd.,1989:456). Örgütsel iklim kurumdaki kaliteyi devam ettirmeye bağlı olarak, çalışanlar tarafından gerçekleştirilen deneyimler ve çalışanların davranışlarının etkileridir (Virtanen, 2000:341).

Litwin ve Stringer (1968) örgütsel iklimi kurumda çalışan bireyin algılarının toplamı olarak tanımlamışlardır. Litwin ve Stringer'a göre iklim, çeşitli davranışlar ile ne tür sonuçların ortaya çıkacağı hakkındaki inançları yönlendirerek kurumsal kararları etkiler. Litwin ve Stringer (1968) 
örgütsel iklimi boyutlara ayırarak tanımlamışlardır. Litwin ve Stringer'ın modeline göre örgütsel iklimin boyutları yapı, sorumluluk, 1lımanlık, destek, ödül, çatışma, standartlar, kurumsal özdeşlik ve risktir. Yapı boyutu, var olan kurallara, düzenlemelere ve yöntemlere ilişkin, çalışanın algılamalarını kapsar. Sorumluluk boyutu, kişinin kendini sorumlu hissetmesi ve inisiyatif kullanabilmesidir. Ödül boyutu, kişinin iyi bir iş yaptığında ödüllendirileceğini hissetmesi durumudur. Risk boyutu, risk alabilme durumunu ve kurumdaki riskleri hesap ederek mücadele edebilmeyi kapsar. Ilımanlık boyutu, bireyin işyerindeki diğer çalışanlarla iyi ilişkiler kurabildiğini hissetmesini içerir. Destek boyutunda çalışan, yöneticiden ve gruptaki diğer çalışanlardan yardım alabileceğini algılar. Standartlar boyutu, çalışan grubu daha iyi olanı yapmaya güdülemek için oluşturulan yüksek standartları kapsar. Çatışma boyutu, çalışanların ve yöneticilerin diğer fikirleri önemsemesi durumudur. Son olarak özdeşleşme boyutu ise çalışanın kendini kuruma ait hissetmesidir.

Hariharan ve Cellular (2005) bilgi yönetimi sürecinin başarısını etkileyen faktörleri liderlik tipi, insan, kültür, teknoloji, işletmenin hedefleri ve bilgi yönetimi sürecinin değerlendirilmesi olarak belirtirler (Akt.Fong, Kwok, 2009:1350). Holsappe ve Joshi (2000) ise bu faktörlere ek olarak örgütsel adalet, çalışan motivasyonu ve dış faktörlerin de bilgi yönetimi sürecini etkilediğini belirtirler. Salavati ve arkadaşları (2010:114) bilgi yönetimi sürecinde örgütsel faktörlerin (bilgi yaratan kültür, liderlik bilgisi, kaynak bilgisi, bilgi temelli yapı ve bilgi temelli süreç), bağlamsal faktörlerden (politik, kültürel ve teknolojik faktörler) daha etkili olduğunu belirtirler. Zhao (2010), olumlu liderliğin, işbirliğinin ve etkileşimin olduğu örgüt ortamında bilgi yönetimi sürecinin daha etkin işlediğini bulmuştur.

Alan yazını incelendiğinde örgüt kültürünün bilgi yönetimi üzerinde etkili olduğunu belirten pek çok teorik ve amprik çalışma olduğu görülmektedir (Yusoff ve Omar, 2011; Davenport ve Prusak, 2000; Janz ve Prasampanic, 2003; Moffett vd, 2003). Çalışmalar öğrenmeyi destekleyen örgüt kültürünün bilgi yönetimi sürecini daha başarılı kıldığını göstermektedir. Örgütsel iklimin bilgi yönetimi üzerindeki etkisini inceleyen çalışmaların alan yazınında yeterli sayıda olmadığ görülmüştür. Yapılan çalışmalarda olumlu örgütsel iklimin bilgi yönetimi sürecinin bir boyutu olan bilgi paylaşımı sürecini olumlu etkilediği bulunmuştur (Bock vd, 2005; Chen vd, 2012). Bu gekçelerden hareketle bu çalışmanın amacı örgütsel iklimi bilgi yönetimi süreci üzerindeki etkisini incelemektir.

\section{Yöntem}

\section{Araştırma Modeli ve Hipotezleri}

$\mathrm{Bu}$ araştırma ilişkisel araştırma modelinde yapılmıştır. Fraenkel, Wallen ve Hyun'a (2006) göre ilişkisel araştırmalar, iki ya da daha çok sayıdaki değişkenler arasındaki ilişkileri, bu değişkenlerin birlikte değişiminin varlığını veya derecesini belirlemeyi amaçlayan araştırmalardır. $\mathrm{Bu}$ araştırmanın yordanan değişkeni bilgi yönetimi sürecidir. Yordayıcı değişken ise örgütsel iklimdir. Araştırmanın amacı İstanbul ilinde Milli Eğitim Bakanlığı’na bağlı okullarda örgütsel iklimin bilgi yönetimi süreci üzerindeki etkisini incelemektir. Araştırmanın hipotezi aşağıda verilmektedir.

H1: Örgütsel iklimi bilgi yönetimi sürecini anlamlı ve pozitif yönde etkilemektedir.

H2:Öğretmenlerin bilgi yönetimi sürecinin gerçekleşme düzeyine ilişkin algıları cinsiyete göre farkl11ık göstermektedir.

H3:Öğretmenlerin bilgi yönetimi sürecinin gerçekleşme düzeyine ilişkin algıları yaşa göre farkl11ık göstermektedir.

H4:Öğretmenlerin bilgi yönetimi sürecinin gerçekleşme düzeyine ilişkin algıları kıdeme göre farkl111k göstermektedir. 
H5:Öğretmenlerin bilgi yönetimi sürecinin gerçekleşme düzeyine ilişkin algıları bilgi yönetimi ile ilgili eğitim alıp almama durumuna göre farkl11ık göstermektedir.

H6:Öğretmenlerin bilgi yönetimi sürecinin gerçekleşme düzeyine ilişkin algıları pozisyona göre farkl1lık göstermektedir.

\section{Evren ve Örneklem}

Araştırmanın örneklemini İstanbul İli Küçükçekmece ilçesinde bulunan, devlet okullarında çalışan 218 öğretmen oluşturmaktadır. Örneklem "tabakalı örneklem” yolu ile belirlenmiştir. Evrende bulunan alt gruplar belirlenmiş, evren içindeki mevcut oranlarına uygun olarak örneklemde temsil edilmeleri sağlanmıştır (Karasar, 2008).

Araştırma anketi, 2018 yılında 6 devlet okulunda gerekli izinler alınarak uygulanmıştır. Katılımcılara 240 anket gönderilmiş, anketlerin 218'si değerlendirmeye alınmıştır. Uygulama sırasında anket formu katılımcılara yüz yüze ulaştırılmıştır. Yanıtlar hazır istatistik paket programı tarafından analiz edilmiştir. Katılımcıların demografik özellikleri ve kurumsal özellikler Tablo 1'de verilmektedir. Tablo 1 incelendiğinde, katılımcıların çoğunluğunu erkek çalışanların oluşturduğu (\%55.9), 20-39 yaş arası (\%67.6) çalışanların çoğunlukta olduğu, çalışanların \%27'sinin bilgi yönetimi konusunda eğitim aldığ 1 görülmektedir.

Tablo 1: Katılımcıların Demografik ve İşe İlişkin Özellikleri

\begin{tabular}{llc}
\hline Değişken & Değişken Değeri & Yüzde (\%) \\
\hline Cinsiyet & Kadın & 44.1 \\
& Erkek & 55.9 \\
\hline Yaş & $20-29$ & 32.4 \\
& $30-39$ & 35.2 \\
& $40-49$ & 19.0 \\
& 50 ve üzeri & 13.4 \\
\hline Çalışsma Yılı & $1-5$ & 33.0 \\
\hline \multirow{3}{*}{} & $6-10$ & 20.7 \\
& $11-15$ & 17.0 \\
& $16-20$ & 17.0 \\
\hline Bilgi Yönetimi Eğitimi & Eğitim Alanlar & 12.8 \\
Alma Durumu & & 27.0 \\
& Eğitim Almayanlar & 73.0 \\
\hline Pozisyon & & 83.1 \\
& Ö̆ğretmen & 11.2 \\
& Müdür Yardımcısı & 5.7 \\
\hline & Müdür & \\
\hline
\end{tabular}

\section{Ölçüm Araçları}

Araştırmada veri toplama aracı olarak "kişisel bilgi formu" ve "örgütsel iklim ölçeği" ve "bilgi yönetimi ölçeği” kullanılmıştır.

1-Kişisel Bilgi Formu: Araştırmacı tarafından hazırlanan kişisel bilgi formu, çalışma grubunda yer alan katılımcıların cinsiyet, yaş, kıdem, bilgi yönetimi ile ilgili eğitim alıp almama durumu, pozisyon bilgilerini içeren toplam 5 sorudan oluşmaktadır.

2- Örgütsel İklim Ölçeği: Ölçek, Litwin ve leeStringer (1968) tarafindan geliştirilmiştir ve 45 maddeyi kapsamaktadır. Yapı, sorumluluk, ödül, 1lımanlık, destek, standartlar, çatışma, özdeşlik ve risk olmak üzere 9 alt boyuttan oluşan ölçek, Nilgün Kalfazade Birim (1993) tarafından Türkçe'ye 
çevrilmiştir (Akt.Tüzün, 2005). Katılımcılardan bu ifadelere ne derece de katıldıklarını "tamamen katılıyorum" dan "hiç katılmıyorum" a doğru uzanan ölçek üzerinde belirtmeleri istenmiştir. Yapılmış olan güvenirlirlik analizi sonucunda ölçeğin \%93 oranında güvenilir olduğu bulunmuştur (cronbach's alpha=0.939) (Töre, 2006:27).

$\mathrm{Bu}$ araştırma kapsamında ilgili örneklem için örgütsel iklim anketine verilen yanıtlar faktör analizine tabi tutulmuş, veriler faktör analizi şartını sağlamadığı için, anket bütün olarak değerlendirilmiştir. Yapılmış olan güvenirlilik analizi sonucunda ölçeğin \%89 oranında güvenilir olduğu bulunmuştur (cronbach's alpha=0.894).

2- Bilgi Yönetimi Ölçeği: Ölçek araştırmacı tarafından ilgili literatür taranarak ve uzman görüşleri alınarak oluşturulmuş̧ur. Ölçek "bilgi toplama" "bilgi üretimi", "bilgi paylaşımı", "bilgi depolama", ve "bilgi kullanımı" olmak üzere beş alt boyutta toplam 22 maddeden oluşmaktadır. Katılımcılardan bu ifadelere ne derece de katıldıklarını "tamamen katılıyorum" dan "hiç katılmıyorum" a doğru uzanan ölçek üzerinde belirtmeleri istenmiştir. Yapılmış olan güvenirlirlik analizi sonucunda ölçeğin \%95 oranında güvenilir olduğu bulunmuştur (cronbach's alpha=0.947).

Bu araştırma kapsamında ilgili örneklem için Bilgi Yönetimi Ölçeği faktör yapılmıştır, analiz sonuçları Tablo 2'de verilmektedir. Yapılan faktör analizi sonucunda Kaise-Meyer-Olkin Ölçüm Yeterliliği .907, Bartlett Test 1512.1062 bulunmuştur $(\mathrm{p}<0.01)$. 3 faktör altında toplanmış olan bilgi yönetimi ölçeği, faktör analizi sonrasında madde sayısını korumuştur. Birinci faktör 12 maddeden oluşmaktadır ve "bilgi üretimi ve paylaşımı " olarak isimlendirilmiştir. İkinci faktör 5 maddeden oluşmaktadır ve "bilgi kullanma ve depolama" olarak isimlendirilmiştir. Üçüncü faktör ise 3 maddeden oluşmaktadır ve "bilgi toplama" olarak isimlendirilmiştir. Bilgi yönetimi anketinin toplam açıklayıcılığı \%66.554, toplam güvenirliği \%94,7 (cronbach’s alpha=0.947) dir.

Tablo 2: Bilgi Yönetimi Ölçeği Faktör Analizi Sonuçları

\begin{tabular}{|c|c|}
\hline $\begin{array}{l}\text { FAKTÖR 1: Bilgi Üretimi ve Paylaşımı (Açılayıcılık= 29.841, } \\
\text { Alpha=.936 ) }\end{array}$ & Faktör Yükü \\
\hline $\begin{array}{l}\text { Madde 14: Çalış̧ı̆ğım işyerinde çalışanlar, işlerin nasıl yapılacağ ile ilgili } \\
\text { birbirlerinin fikirlerine başvururlar. }\end{array}$ & .782 \\
\hline $\begin{array}{l}\text { Madde 10: Çalıștığım işyerinde çalışanlar, bir işi iyi yapan çalışandan, o } \\
\text { işin nasıl yapıldığını öğrenmeye çalışılar. }\end{array}$ & .728 \\
\hline $\begin{array}{l}\text { Madde 11: Çalıştığım işyerinde çalışanlar, öğrendikleri yeni bilgileri ve } \\
\text { kavramları işyerine aktarırlar. }\end{array}$ & .724 \\
\hline $\begin{array}{l}\text { Madde 13: Çalıștı̆̆ım işyerinde çalışanlar, deneyimlerini ihtiyaç } \\
\text { duyanlarla paylaşılar }\end{array}$ & .711 \\
\hline $\begin{array}{l}\text { Madde 4: Çalıştı̆̆ım işyerinde, çalışanlar bir işe başlamadan önce iş } \\
\text { arkadaşlarının fikrini alır. }\end{array}$ & .698 \\
\hline $\begin{array}{l}\text { Madde 5: Çalıştı̆ı̆m işyerinde, işle ilgili var olan bilgilerden yeni bilgi } \\
\text { üretilir. }\end{array}$ & .689 \\
\hline Madde 12: Çalıştığım işyerinde, edinilen bilgi yeni bir ürüne dönüştürülür. & .666 \\
\hline $\begin{array}{l}\text { Madde 18: Çalıştığım işyerinde çalışanlar, bilgiyi ihtiyaç duyan herkesin } \\
\text { ulaşabileceği hale getirirler. }\end{array}$ & .665 \\
\hline $\begin{array}{l}\text { Madde 15: Çalıştı̆̆ım işyerinde çalışanlar, edindiği güncel bilgi ve } \\
\text { kavramları işyerinde kullanırlar. }\end{array}$ & .636 \\
\hline $\begin{array}{l}\text { Madde 9: Çalıştı̆̆ım işyerinde çalışanlar sahip oldukları bilgiyi tüm } \\
\text { işyerine dağıtılırlar. }\end{array}$ & .596 \\
\hline Madde 7: Çalıştı̆ım işyerinde, bilginin güncellenmesini sağlanır. & .567 \\
\hline $\begin{array}{l}\text { Madde 6: Çalıştığım işyerinde, bir iş yapıııırken işle ilgili prosedür } \\
\text { geliştirilir. }\end{array}$ & .474 \\
\hline
\end{tabular}

Turkish Studies - Education, 15(3) 


\begin{tabular}{lc}
\hline FAKTÖR 2:Bilgi Kullanma ve Depolama (Açıklayıcılık= 20.537, & Faktör Yükü \\
Alpha=.842 ) & \\
\hline $\begin{array}{l}\text { Madde 19: Çalıştığım işyerinin arşivindeki bilgiler çalışanlarca kullanılır. } \\
\text { Madde 20: Çalıştığım işyerinde çalışanlar, bir işi yaparken yaptıkları }\end{array}$ & .722 \\
$\begin{array}{l}\text { iş ile ilgili düzenli not tutarlar. } \\
\text { Madde 17: Çalıştığım işyerinde çalışanlar, bilişim teknolojisini }\end{array}$ & .704 \\
kullanırlar. & .673 \\
$\begin{array}{l}\text { Madde 18: Madde 19: Çalıştığım işyerinde, iş için gerekli bilgi düzenli } \\
\text { olarak dosyalanır. }\end{array}$ & .614 \\
$\begin{array}{l}\text { Madde 16: Çalışma ortamınız her çalışanın yeteneklerini kullanmasına } \\
\text { olanak sağlar. }\end{array}$ &
\end{tabular}

FAKTÖR 3: Bilgi Toplama (Açıklayıcılık=16.176, Alpha=.893 ) $\quad$ Faktör Yükü

Madde 3: Çalıştığım işyerinde, bir işe başlamadan önce o işle ilgili

.881

dosyalar/ veri tabanları gözden geçirilir.

Madde 2: Çalıştığım işyerinde, bir işe başlamadan önce işle ilgili daha

önceden yapılmış çalışmalar detaylı incelenir.

Madde 1:Çalıştığım işyerinde, bir işe başlamadan önce o işle ilgili

yöneticilerden detaylı bilgi alınır.

.806

\section{Verilerin Analizi}

Araştırma sorularını yanıtlamada, betimsel istatistikler, faktör analizi, regreston analizi, katılımcıların demografik ve işe ilişkin özelliklerine göre ayrı ayrı gruplarda bağlantısız örneklemler için t testi ve ANOVA testi analizi kullanılmıştır. Analizler öncesinde veriler, temel varsayımlar açısından incelenmiş ve gerekli düzeltmeler yapılmıştır. Öncelikle veri setindeki kayıplar değerlendirilmiştir. Yordanan ve yordayıcı değişkenlerde, her bir madde düzeyinde kayıpların en fazla \%2 olduğu, cinsiyet ve diğer değişkenlerle manidar bir ilişki göstermediği görülmüştür. Maddelerin sıralama ölçeğinde veri sağladığı dikkate alınarak, kayıp veri atama yöntemlerinden medyan atama kullanılarak eksiksiz veri elde edilmiştir. Yordanan ve yordayıcı değişkenlere yönelik toplam puanlar, standart $Z$ puan dönüşümü kullanılarak uç değerler açısından incelenmiştir. $(-3,+3)$ standart değerleri dışında değer alan iki gözlem birimi belirlenmiş, bunlar uçdeğer olarak tanımlanmış ve veri setinden çıkarılmıştır.

Değişkenlerin doğrusallıklarını incelemek için standardize edilmiş artık değerler ile standardize edilmiş yordanan değerler için saçılma diyagramları, histogram ve normal dağılım eğrileri oluşturulmuştur (Büyüköztürk, 2013). Grafiklere göre, noktaların bir eksen etrafinda toplanarak doğrusallık varsayımını karşıladığı görülmüştür. Otokorelasyonu test etmek amaciyla Durbin Watson değeri incelenmiştir. Durbin Watson katsayısı olayların sırası ile ilgili hataların otokorelasyonunun ölçümü ile ilgilidir ve bu katsayının anlamlı çıkması hataların bağımlılığını göstermektedir (Tabachnick ve Fidell, 2007). Bu değerin 1.99 olduğu görülmüş olup, 2'ye yakın değerler otokorelasyonun olmadığını ifade etmektedir (Kalaycı, 2014).

\section{Bulgular}

$\mathrm{Bu}$ bölümde araştırma soruları çerçevesinde ulaşılan bulgulara yer verilmektedir. Araştırmanın 1. hipotezini test etme amacı ile yapılan regresyon analizi sonucunda, örgütsel iklimin bilgi yönetimi sürecini anlamlı ve pozitif yönde etkilediği $[(\mathrm{B}=.758),(\mathrm{p}<0.01)]$ ve modeli $\% 57$ oranında açıkladığı bulunmuştur (Tablo 3). 
Tablo 3: Örgütsel İklimin Bilgi Yönetimi Süreci Üzerindeki Etkisini İnceleyen Regresyon Analizi Sonuçları

\begin{tabular}{ccccccc}
\hline & \multicolumn{5}{c}{ Bilgi Yönetimi Süreci } \\
\hline \multirow{2}{*}{ Örgütsel } & $\mathbf{R}^{2}$ & $\Delta \mathrm{R}^{2}$ & $\mathrm{~F}$ & $\mathrm{~B}$ & $\mathrm{t}$ & P Değeri \\
\cline { 2 - 7 } İklim & .574 & .569 & 107.764 & .758 & 10.381 & $.000^{* *}$ \\
\hline \multirow{**}{*}{$\mathrm{p}<0.01$} & & & & & &
\end{tabular}

$* * \mathrm{p}<0.01$

Örgütsel iklimin bilgi yönetimi sürecinin alt boyutlarını nasıl yordadığını bulmak üzere yapılan regresyon analizi sonucunda, örgütsel iklimin bilgi yönetimi sürecinin "bilgi üretimi ve paylaşımı" alt boyutunu anlamlı ve pozitif yönde etkilediği $[(\mathrm{B}=.739),(\mathrm{p}<0.01)]$ ve modeli \%54 oranında açıkladığı bulunmuştur (Tablo 4).

Tablo 4: Örgütsel İklimin Bilgi Yönetimi Sürecinin "Bilgi Üretimi ve Paylaşımı” Boyutu Üzerindeki Etkisini İnceleyen Regresyon Analizi Sonuçları

\begin{tabular}{ccccccc}
\hline & \multicolumn{7}{c}{ Bilgi Üretimi ve Paylaşımı } \\
\hline Örgütsel & $\mathbf{R}^{2}$ & $\Delta \mathrm{R}^{2}$ & $\mathrm{~F}$ & $\mathrm{~B}$ & $\mathrm{t}$ & P Değeri \\
\cline { 2 - 7 } İklim & .546 & .540 & 97.272 & .739 & 9.863 & $.000^{* *}$ \\
\hline$* * \mathrm{p}<0.01$ & \multicolumn{7}{c}{} & & & & &
\end{tabular}

Örgütsel iklimin bilgi yönetimi sürecinin "bilgi kullanma ve depolama" alt boyutunu anlamlı ve pozitif yönde etkilediği $[(\mathrm{B}=.665),(\mathrm{p}<0.01)]$ ve modeli $\% 44$ oranında açıkladığı bulunmuştur (Tablo 5).

Tablo 5: Örgütsel İklimin Bilgi Yönetimi Sürecinin "Bilgi Kullanma ve Depolama” Boyutu Üzerindeki Etkisini İnceleyen Regresyon Analizi Sonuçları

\begin{tabular}{ccccccc}
\hline \multicolumn{7}{c}{ Bilgi Kullanma ve Depolama } \\
\hline Örgütsel & $\mathbf{R}^{2}$ & $\Delta \mathrm{R}^{2}$ & $\mathrm{~F}$ & $\mathrm{~B}$ & $\mathrm{t}$ & P Değeri \\
\cline { 2 - 7 } İklim & .443 & .436 & 65.945 & .665 & 8.121 & $.000^{* *}$ \\
\hline \multirow{**}{*}{$\mathrm{p}<0.01$} & & & & & &
\end{tabular}

Örgütsel iklimin bilgi yönetimi sürecinin "bilgi toplama" alt boyutunu anlamlı ve pozitif yönde etkilediği $[(\mathrm{B}=.436(\mathrm{p}<0.01)]$ ve modeli $\% 18$ oranında açıkladığı bulunmuştur (Tablo 6).

Tablo 6: Örgütsel İklimin Bilgi Yönetimi Sürecinin "Bilgi Toplama” Boyutu Üzerindeki

Etkisini İnceleyen Regresyon Analizi Sonuçları

\begin{tabular}{ccccccc}
\hline \multicolumn{7}{c}{ Bilgi Toplama } \\
\hline Örgütsel & $\mathbf{R}^{2}$ & $\Delta \mathrm{R}^{2}$ & $\mathrm{~F}$ & $\mathrm{~B}$ & $\mathrm{t}$ & P Değeri \\
\cline { 2 - 7 } İklim & .190 & .180 & 19.672 & .436 & 4.445 & $.000^{* *}$ \\
\hline$* * \mathrm{p}<0.01$ & & & & & &
\end{tabular}

Yapılan T-testleri ve ANOVA testleri sonucunda öğretmenlerin bilgi yönetim sürecine ilişkin algılarının yaş, çalışma yılı ve pozisyon değişkenlerine göre farklılaştığı; cinsiyet ve bilgi yönetimi konusunda eğitim alıp almama durumuna göre farklılaşmadığı bulunmuştur.

Yaş değişkenine göre, bilgi yönetim süreci puanları ve varyans analizi sonuçları Tablo 7'de verilmektedir. Tablo 7 incelendiğinde $40-49$ yaş arası olan öğretmenlerin, diğerlerine göre; 50 yaş ve üzeri olan öğretmenlerin 20-29 yaş arası ve 30-39 yaş arası öğretmenlere göre bilgi yönetimi 
sürecinin gerçekleşme düzeyine ilişkin algılarının daha yüksek olduğu görülmektedir ( $\mathrm{F}=4.067$, $\mathrm{p}<0.01)$.

Tablo 7 : Yaş Değişkenine Göre Bilgi Yönetimi Süreci Puanları ve Varyans Analizi

\begin{tabular}{cccccccc} 
& \multicolumn{7}{c}{ Sonuçları } \\
\hline Bilgi & Yaş & $\mathrm{N}$ & Ort. & $\mathrm{S}$ & $\mathrm{F}$ & $\mathrm{p}$ & Fark-Grup \\
\hline $\begin{array}{c}\text { Yönetimi } \\
\text { Süreci }\end{array}$ & $\begin{array}{c}20-29 \text { yaş } \\
\text { aras1 }\end{array}$ & 66 & 68.84 & 11.02 & 4.067 & $.009^{* *}$ & $3-1$ \\
\cline { 2 - 8 } & $\begin{array}{c}30-39 \text { yaş } \\
\text { aras1 }\end{array}$ & 81 & 71.97 & 14.56 & & & $3-2$ \\
\hline $\begin{array}{c}40-49 \text { yaş } \\
\text { aras1 }\end{array}$ & 39 & 81.00 & 11.65 & & & $4-4$ \\
& $\begin{array}{c}50 \text { yaş ve } \\
\text { üzeri }\end{array}$ & 32 & 77.35 & 10.35 & & & $4-2$ \\
\hline$* * \mathrm{p}<0.01$ & & & & & \\
\hline
\end{tabular}

Çalışma yılı değişkenine göre, bilgi yönetim süreci puanları ve varyans analizi sonuçları Tablo 8'de verilmektedir. Tablo 8 incelendiğinde çalışma yılı 16-20 yıl arası olan öğretmenlerin, diğerlerine göre; çalışma yılı 20 yıl ve üzeri öğretmenlerin çalışma yılı 1-5 yıl arası, 6-10 yıl arası ve 11-15 yıl arası olan öğretmenlere göre; çalışma yılı 11-15 yıl arası öğretmenlerin çalışma yılı 15 yıl ve 6-10 yıl arası olan öğretmenlere göre bilgi yönetimi sürecinin gerçekleşme düzeyine ilişkin algılarının daha yüksek olduğu görülmektedir $(\mathrm{F}=4.462, \mathrm{p}<0.05)$.

Tablo 8 : Çalışma Yılı Değişkenine Göre Bilgi Yönetimi Süreci Puanları ve Varyans Analizi Sonuçları

\begin{tabular}{|c|c|c|c|c|c|c|c|}
\hline & Çalışma Yılı & $\mathrm{N}$ & Ort. & $S$ & $\mathrm{~F}$ & $\mathrm{p}$ & Fark-Grup \\
\hline \multirow{7}{*}{$\begin{array}{c}\text { Bilgi } \\
\text { Yönetimi } \\
\text { Süreci }\end{array}$} & $1-5$ y1l aras1 & 71 & 68.06 & 11.72 & 4.462 & $.011 *$ & $3-1$ \\
\hline & & & & & & & $3-2$ \\
\hline & 6-10 y1l & 48 & 68.84 & 12.80 & & & $4-1$ \\
\hline & aras1 & & & & & & $4-2$ \\
\hline & $\begin{array}{c}11-15 \text { yil } \\
\text { aras1 }\end{array}$ & 38 & 74.00 & 16.07 & & & $4-3$ \\
\hline & $\begin{array}{c}16-20 \text { y1l } \\
\text { aras1 }\end{array}$ & 34 & 78.92 & 13.85 & & & $\begin{array}{l}5-1 \\
5-2\end{array}$ \\
\hline & $\begin{array}{c}20 \text { yil ve } \\
\text { üzeri }\end{array}$ & 27 & 80.81 & 5.63 & & & $5-3$ \\
\hline
\end{tabular}

Pozisyon değişkenine göre bilgi yönetim süreci puanları ve varyans analizi sonuçları Tablo 9'da verilmektedir. Tablo 9 incelendiğinde okul müdürlerinin, müdür yardımcısı ve öğretmenlere göre bilgi yönetimi sürecini gerçekleşme düzeyine ilişkin algılarının daha yüksek olduğu görülmektedir $(\mathrm{F}=5.484, \mathrm{p}<0.01)$.

Tablo 9 : Pozisyon Değişkenine Göre Bilgi Yönetimi Süreci Puanları ve Varyans Analizi Sonuçları

\begin{tabular}{|c|c|c|c|c|c|c|c|}
\hline & Pozisyon & $\mathrm{N}$ & Ort. & $\mathrm{S}$ & $\mathrm{F}$ & $\mathrm{p}$ & Fark-Grup \\
\hline \multirow{3}{*}{$\begin{array}{l}\text { Bilgi } \\
\text { Yönetimi } \\
\text { Süreci }\end{array}$} & Öğretmen & 175 & 71.25 & 12.55 & 5.484 & $.002 * *$ & $3-1$ \\
\hline & & & & & & & $3-2$ \\
\hline & $\begin{array}{c}\text { Müdür } \\
\text { Yardımcis1 }\end{array}$ & 27 & 69.11 & 13.67 & & & \\
\hline & Müdür & 16 & 89.20 & 8.70 & & & \\
\hline
\end{tabular}




\section{Tartışma ve Sonuç}

$\mathrm{Bu}$ çalışmada örgütsel iklimin bilgi yönetimi süreci üzerindeki etkisini incelenmiştir. Araştırma sonucunda, örgütsel iklimin bilgi yönetimi süreci üzerindeki etkili olduğu bulunmuştur. Yapılacak işlerin açıç̧a belirtilmiş olduğu, yeni ve yaratıcı fikirlerin önemsendiği, çalışanlar arasında iyi ilişkilerin olduğu örgütlerde; bilgi yönetimi süreci daha etkin işlemektedir. Çalışanların örgütsel iklimi olumlu algıladığı örgütlerde sırası ile "bilgi üretimi ve paylaşımı", "bilgi kullanma ve depolama" ve "bilgi toplama" süreçleri daha yüksek oranda gerçekleşmektedir.

Chen ve Huang (2007) örgütsel iklimin ve yapının bilgi yönetimi üzerindeki etkilerini inceledikleri araştırmalarında, yenilikçi ve destekleyici iklimin bilgi yönetimi ile pozitif anlamlı ilişki içerisinde olduğunu bulmuşlardır. Lee ve arkadaşları (2006) öğrenme odaklı olma, güven ve çalışan bağl1lı̆̆ kavramlarını içeren iklim olgunluğunun bilgi yönetimi performansını pozitif anlamlı etkilediğini bulmuşlardır. Lin ve Lee (2006) örgütsel iklimin algılanan göreceli avantaj1, uyumluluğu ve karmaşıklığı önemli ölçüde etkilediğini ve bunun da bilgi paylaşımını teşvik etme niyetini olumlu yönde etkilediğini bulmuşlardır. Zhao (2010), olumlu liderliğin, işbirliğinin ve etkileşimin olduğu örgüt ortamında bilgi yönetimi sürecinin daha etkin işlediğini bulmuştur. Olumlu örgütsel iklimin bilgi yönetiminin bir boyutu olan bilgi paylaşımı sürecini olumlu etkilediğini belirten araştırmalarda alanyazında mevcuttur (Li vd., 2010, Villamizar Reyes, Castañeda Zapata, 2014; Bock vd, 2005; Chen vd, 2012). Bock ve arkadaşları (2005) adil, yenilikçi ve yakın ilişkilerin hakim olduğu örgüt ikliminde bilgi paylaşımı sürecinin daha etkin işlediğini bulmuştur. Bilişim teknolojisi işletmelerinde çalışanların bilgi paylaşımı davranışını inceleyen Li ve arkadaşları (2010) örgütsel iklimin (arkadaşça ilişkiler, inovasyon ve adalet) çalışanın bilgi paylaşım davranışını etkilediğini bulmuşlardır. Bu bulgular araştırmamızı destekler niteliktedir.

$\mathrm{Bu}$ çalışmada 40-49 yaş arası olan öğretmenler ile 50 yaş ve üzeri olan öğretmenlerin, 2029 yaş arası ve 30-39 yaş arası ögretmenlere göre bilgi yönetimi sürecini gerçekleşme düzeyine ilişkin algılarının daha yüksek olduğu görülmektedir. Ayrıca çalışma yılı 16-20 yıl arası olan öğretmenleri ile çalışma yılı 20 yıl ve üzeri öğretmenlerin, çalışma yılı 1-5 yıl arası ve 6-10 yıl arası olan öğretmenlere göre bilgi yönetimi sürecinin gerçekleşme düzeyine ilişkin algılarının daha yüksek olduğu görülmektedir. Yaş ve çalışma yılı arttıça bilgi yönetimi sürecine ilişkin olumlu algı geliştirme durumu öğretmenlerin sisteme ve işe dair kazandıkları deneyimler ile açıklanabilir.

Araştırma bulguları okul müdürlerinin, müdür yardımcısı ve öğretmenlere göre bilgi yönetimi sürecini gerçekleşme düzeyine ilişkin algılarının daha yüksek olduğu göstermektedir. Okul müdürlerinin yönetim sürecinin başında olan kişiler olması ve bilgi yönetimi sürecinin bütünün görebilmesi bu olumlu algının nedeni olabilir.

Araştırmanın bulguları doğrultusunda aşağıdaki önerilere yer verilmektedir.

- Bilgi yönetimi sürecinin kilit değişken olduğu eğitim örgütlerinin, örgütsel iklimlerini olumlu k1lacak stratejilere yer vermesi önerilmektedir.

- Çalışma yılı 1-10 yıl arası olan öğretmenlerin bilgi yönetimi sürecinin gerçekleşme düzeyine ilişkin algıları daha tecrübeli öğretmenlere göre düşük bulunmuştur. Tecrübeli öğretmenlerin süreç ile ilgili daha az tecrübeli öğretmenlere rehberlik etmelerinin faydalı olacağ düşünülmektedir.

- Okul müdürlerinin bilgi yönetimi sürecinin gerçekleşme düzeyine ilişkin algıları, müdür yardımcıları ve öğretmenlere göre düşük bulunmuştur. Bu durumun nedenlerinin araştırılmasına yönelik nitel çalışmalar yapılabilir.

- Araştırma İstanbul ili, Küçükçekmece ilçesinde çalışan öğretmenler ile sınırlı tutulmuş olup, farklı illerde ve farklı meslek gruplarında yapılması önerilmektedir. 
- Bu araştırmada bilgi yönetimi süreci öğretmenler tarafından değerlendirilmiştir. Sonraki araştırmalarda öğrenciler, veliler ve diğer paydaşlar değerlendirme sürecine dâhil edilerek; daha kapsamlı bir çalışmaya gidilebilir.

- Bilgi yönetimi sürecini etkileyen diğer örgütsel ve bireysel değişkenlerin de incelenmesi önerilmektedir.

\section{Kaynakça}

Anand, A., Singh, M.D. (2011). "Understanding knowledge management: a literature review". International Journal of Engineering Science and Technology, 3(2):926-939.

Bock, G., Zmud, R., Kim, Y., Lee, J. (2005). "Behavioral intention formation in knowledge sharing: examining the roles of extrinsic motivators, social-psychological forces, and organizational climate". MIS Quarterly, 29 (1):87-111.

Büyüköztürk, Ş. (2013). Sosyal bilimler için veri analizi el kitabı. (Genişletilmiş 18. Bask1). Ankara: Pegem Akademi.

Chen, S., Chuang,Y., Chen, P. (2012). "Behavioral intention formation in knowledge sharing: examining the roles of KM's quality, KM's self-efficacy, and organizational climate". Knowledge-Based Systems, 31:106-118.

Chen, C. J., Huang, J. W. (2007). "How organizational climate and structure affect knowledge management-The social interaction perspective", International journal of information management, 27(2), 104-118. Purpose

Çetinkaya, A. (2012). “Örgütsel bilgi yönetim sürecinde bilgi yönetim performansı boyutları: ölçek geliştirme ve geçerliliği üzerine bir çalışma”. Öneri Dergisi, 10:157-162.

Çınar, İ. (2004). "Bilgi yönetiminde eğitim yöneticiliklerin yeterlilikleri: Malatya örneği”, 13. Ulusal Eğitim Bilimleri Kurultayı. İnönü Üniversitesi Eğitim Fakültesi.

Davenport, T.,Prusak, L. (2000). Working knowledge: how organization manage what they know. Harward Business School Press.

Dawis, K., Newstrom, J.W. (1985). Human behavior at work: organizational behavior. New York: Mc-Graw Hill Book.

Fard, H.D., Selseleh, M. (2010) "Measuring knowledge management cycle: Evidence from Iran", European Journal of Scientific Research, 41 (2):297-309.

Fong, P., Kwok, C.(2009) "Organizational culture and knowledge management success at project and organizational levels in contracting firms", Journal of Construction Engineering and Management, December, s.1348-1356.

Fraenkel, J. R., Wallen, N. E., Hyun, H. H. (2006). How to Design and Evaluate Research in Education (6.Bask1). McGraw-Hill.

Ghorbani M., Noghabani J., Nikoudar M. (2011) "Relationship between organizational structure dimentions and knowledge management in education organization", World Applied Science Journal, 2 (11):2032-2040.

Halis, M., Uğurlu, Ö. "Güncel çalışmalar 1şı̆̆ında örgüt iklimi”, “İş, Güç” Endüstri Illişkileri ve Insan Kaynakları Dergisi”, 10(2), 101-123.

Hoy, W. (1990). "Organizational climate and culture: a conceptual analysis of the school workplace", Journal of Educational and Psychological Consultation, 7 (2):149-168. 
Holsapple, C. W., Joshi, K. D. (2000). "An investigation of factors that influence the management of knowledge in organizations", The Journal of Strategic Information Systems, 9(2-3), 235261.

Kalaycı, Ş. (2014). SPSS Uygulamalı Çok Değişkenli İstatistik Teknikleri. Asil Yayınevi.

Karasar, N. (2008). Bilimsel araştırma yöntemi: kavramlar-ilkeler-teknikler. Nobel Yayın Dağıtım.

Kılıç, İ. (2007). "Ĕğitim yöneticilerinin bilgi yönetimindeki yeterlilikleri”, Selçuk Üniversitesi Sosyal Bilimler Enstitüsü, Yayınlanmamış Yüksek Lisans Tezi.

Kourik, J; Maher, P. (2008). "Does practice reflect theory? an exploratory study of succesful knowledge management system", Proceeding of World Academy of Science, Engineering and Technology, November, 35:5-13.

Janz B.D., Prasamphanic, P. (2003). "Understanding the ancedents of effective knowledge management: the importance of knowledge-centered culture", Decision Science, 34(2): 351-373.

Lee, J. H., Kim, Y. G., Kim, M. Y. (2006). "Effects of managerial drivers and climate maturity on knowledge-management performance: Empirical validation", Information Resources Management Journal (IRMJ), 19(3), 48-60.

Lewin, K., Lippitt, R., White R. (1939). "Patterns of aggressive behavior in experimentally created "social climates"”. Journal of Social Psychology, 10:271-299.

Li, Z., Zhu, T., Luo, F. (2010). "A Study on the Influence of Organizational Climate on KnowledgeSharing Behavior in IT Enterprises", JCP, 5(4), 508-515.

Lin, H. F., Lee, G. G. (2006). "Effects of socio-technical factors on organizational intention to encourage knowledge sharing", Management decision, 44(1), 74-88.

Litwin, G., Stringer. (1968). Motivation and Organizational Climate. Harward University Pres.

Moffet, S., Mc Adam R.,Parkinson S. (2003). "An amprical analysis of knowledge management applications", Journal of Knowledge Management, 7 (3):6-26.

Porter, L.W., Lawler, E.E., Hackman, R.J. (1987). Behavior in Organizations. Mcgraw Hill International Editions.

Saade, R, Nebebe, F., Tak, M. (2011). "Knowledge management system development: theory and practice", Interdiciplinary Journal of Information, 6, 35-72.

Salavati, A., Shafei, R., Shaghayegh, E. (2010). "A model for adoption of knowledge management in Iranian public organizations”, European Journal of Social Sciences, 17(1):109-116.

Tabachnick, B. G., Fidell, L. S. (2007). Using multivariate statistics. Allyn \& Bacon/Pearson Education.

Tabrizi, R. S., Foong, Y. P., Ebrahimi, N. (2010) "Knowledge management criteria among malasian organizations: an anova approach", World Academy of Science, Engineering and Technology,4(12), 2265 - 2269.

Töre, E. (2006) "The effect of organizational climate and organizational commitment on unethical behavior at work", Marmara Üniversitesi Sosyal Bilimler Enstitüsü, Yayınlanmamış Yüksek Lisans Tezi.

Tüzün, T. (2005). "Management practices as determinant of organizational climate and the effect of climate on job satisfaction", Marmara Üniversitesi Sosyal Bilimler Enstitüsü, Yayınlanmamış Yüksek Lisans Tezi. 
Villamizar Reyes, M. M., Castañeda Zapata, D. I. (2014). "Relation between organizational climate and its dimensions and knowledge-sharing behavior among knowledge workers", International Journal of Psychological Research, 7(2), 64-75.

Virtanen, T. (2000). "Commitment and study of organizational climate and culture". Handbook of Organizational Culture and Climate. Thousand Oaks, Calif.,Sage Publications.

Walczak (2005) "Organizational knowledge management structure", The Learning Organization, 12(4), 330-339.

Yusoff, W.F., Omar, S. A. (2011) "Knowledge management strategy and design: the role of corporate culture", International Journal of Interdisciplinary Social Sciences, 6 (2):145154.

Zhao, J. (2010). "School knowledge management framework and strategies: the new perspective on teacher professional development", Computer in Human Behavior, 26:168-175. 